\title{
Service Supply Chain Planning for Industrial Services - Design and Application of a Decision Support Tool
}

\author{
Philipp Hertz ${ }^{*}$ and Alexander Sproedt \\ ETH Zurich, BWI Center for Industrial Management, \\ 8092 Zurich, Switzerland \\ \{phertz, asproedt\}@ethz.ch
}

\begin{abstract}
Industrial services such as classical MRO-services and also advanced offerings, e.g. performance based contracting, are gaining importance in the machine and equipment industry. From a niche the business units responsible for service have grown to major contributors to the success of the company. Meanwhile operations have grown historically and service manager struggle to professionalize their service operations to improve efficiency. In this contribution we provide an overview of 3 cases of companies trying to gain competitiveness by using a simulation-based decision support system for field service supply networks.
\end{abstract}

Keywords: Service supply chain, field service, network planning, decision support, case study, after-sales.

\section{Introduction}

In the last years many companies have shifted away from the traditional business of offering manufactured goods only to create more customer value by selling industrial product-service systems based on a the trend called "servitization"'[1]. The reasons for that are manifold. Financially services contribute to a high ratio of the profit in most companies as the service business still provides the opportunities for high margins for reactive repairs or critical spare parts [2]. Additionally services allow to maintain a customer relationship during the life cycle of the sold product and provide increased customer value which benefits customer loyalty and the potential to react on the feedback of the customer for future product developments [3].

Therefore industrial field services have gained importance in the business of western manufacturing companies for years and became a critical factor for the profitability and competiveness in many cases. These services include basic contracts for pro- und reactive maintenance activities as well as advances offerings such as technical consulting or retrofitting [4].

Field service supply networks (FSSNs), as a special kind of service delivery systems, incorporate the technical support in form of service technicians in and off the field and a supply network for the delivery of spare parts. Both parts of the field

\footnotetext{
* Corresponding author.
} 
service network have to work cooperatively to fulfill SLAs at lowest cost. Thereby service mangers face among other problems uncertain and lumpy demand, heterogenic technical and customer requirements with different performance targets, a highly scattered installed base with a variety of technologies and generations of asset from different centuries [5]. This requires a highly skilled and flexible workforce that can provide service in a timely manner over a certain region. But many companies still struggle with historical structures, lack of transparency and rising costs while customer demand more complex services, e.g. availability or performance based contracting, for reasonable prices.

Though the importance of the service business for manufacturing companies is beyond dispute, and many researcher and practitioners have stressed the "urgency for rigorous study to guide service managers in improving the design, competitiveness, efficiency and effectiveness of service delivery" decision makers today are still missing decision support tools [6]. Most methods used to investigate or improve service operations to professionalize service operations in field service networks are outdated and overly simplistic [7]. Therefore we will investigate the area of FSSNs planning and decision support in the following.

\section{Literature Review}

\subsection{Field Service Network Planning}

Decision support systems are "interactive computer-based systems that help people use computer communications, data, documents, knowledge, and models to solve problems and make decisions" [8]. Their purpose is to support decision-making without before any kind of changes is conducted. This is of upmost importance for the service business, as changes in the field service network are costly while their effects on the performance of the systems, e.g. in terms of responsiveness or costs, can hardly be anticipated. In the following we want to detail the different decisions to be made in FSSN design and planning shortly, before we will analysis contributions from literature and practices in industry.

Similarly to Advanced Planning in Supply Chain Management, field service planning includes different varies planning tasks that need to be conducted to design the "people and parts" network over different time horizons [9]. On a strategic and longterm horizon this includes districting of the installed base into decoupled territories which that are covered by a common a set of resources for a certain service [7, 10], the definition of skill sets for technicians and the right target mix in the workforce $[11,12]$, as well as the selection of locations for facilities [13]. Mid-term process design, including the definition of dispatching rules for the assignment of tickets to technicians [14, 15], and capacity, e.g. manpower and inventory, planning for each location becomes relevant [7]. All these planning tasks are highly interrelated and therefore hard to optimize individually. Furthermore, small changes in such a complex system might lead to a totally different behavior of the entire system [16, 17]. Therefore also high-level decision support should rely on the analysis of the realistic behavior of the complex system as a whole. 


\subsection{Decision Support for Field Service Network Planning}

State of the art software packages mostly offer planning support on an operational level by providing optimization algorithms or visual presentations of the work load based on real time data to enhance the information that is available for dispatchers. On a strategic or tactical level these software packages offer only limited support (Rapaccini et al., 2008).

In literature a variety of contribution of different authors can be found that have developed mathematical programming or queuing models to support single or multiple planning tasks of FSSN design [13, 17-20]. Based on shortcomings of these approaches such as the limited the problem's complexity $[7,16]$ or the use of deterministic model parameters in such a uncertain environment which make most contributions only moderately applicable, simulation has been chosen as underlying technique to provide heuristic "("What-If") support" by applying proper design of experiment [21, 22]. The most relevant contributions based on the use of simulation to support decision making in this context can be clustered in different parts. On a tactical level support staffing, process design, or more specifically dispatching policies, are investigated based on response time and utilization indicators by Hill [15], Watson et al. [7], Dear [16], Visser [23] and Duffuaa and Raouf [24]. Another important class of contributions focuses on the optimal qualification and dispatching strategies in manpower planning for different scenarios [25-27]. Focus here lies on the degree of cross training and pooling effects within the workforce. Only a few contributions integrate several aspects of field service network design as for example Rapaccini et al. [28].

Though all contributions provide important insides into the challenges of operations management for field services, they lack important characteristics to be applicable for modeling and analyzing a FSSN holistically. An overview of the evaluation of the most important contributions is given in table 1 .

Table 1. Relevant contributions in FSSN simulation

\begin{tabular}{|c|c|c|c|c|c|c|c|c|c|}
\hline \multirow[b]{2}{*}{ Author } & \multirow[b]{2}{*}{ Focus } & \multicolumn{8}{|c|}{ Modeling Detail } \\
\hline & & Demand & $\begin{array}{c}\text { Network } \\
\text { struc- } \\
\text { ture }\end{array}$ & Product & Services & Process & $\begin{array}{c}\text { Dispatch } \\
\text { \& rout- } \\
\text { ing }\end{array}$ & $\begin{array}{l}\text { Employ- } \\
\text { ees }\end{array}$ & $\begin{array}{l}\text { Spare } \\
\text { parts }\end{array}$ \\
\hline Homer & $\begin{array}{l}\text { S, Dist, } \\
\text { RT }\end{array}$ & & & & & & & & \\
\hline $\begin{array}{l}\text { Watson et } \\
\text { al. }\end{array}$ & S, RT & & & & & & & & \\
\hline Dear & S, Disp & & & & & & & & \\
\hline Rapaccini et & $\begin{array}{l}\text { Dist, } \\
\text { Disp, CT }\end{array}$ & & & & & & & & \\
\hline Colen and & CT & & & & & & & 7 & \\
\hline Lambrecht & & & & & & & & & \\
\hline
\end{tabular}

Underline:

$\mathrm{S}=$ Staffing, Disp=Dispatching, RT=Response time, Dist=Districing, C=contracting, CT=cross-training

$O_{\text {not considered }} O_{\text {moderate }} O_{\text {advanced }}$ fully 


\section{Project Background and Methodology}

The introduction and literature review have revealed a gap in academia and practice alike in regard to appropriate methods to assist service managers in designing and planning their FSSN. Based on the decision prior made to use discrete event simulation as a technique to support decision making, the following research questions have been formulated in regard to the development of a DSS:

1. How can decision making for designing an industrial FSSN in different industries be supported adequately by a DSS based on discrete event simulation?

a. What are the different entities that have to be considered in such a model and how do they interact?

b. Which performance indicators are needed to support decision making for the different planning problems?

2. Which insights can be drawn from the application of such a DSS?

The project AsPlanned provided the starting point for this research. The aim of the project was to develop a decision support tool based on discrete-event simulation. The software should support decision-making in field service network planning for different planning tasks, e.g. the districting of field service networks or location and capacity planning for the technical field support and the spare parts supply chain. Efforts for modeling and using the software should be reduced by explicitly adapting it to the needs of FSSN planning while the generalizability and therefore wide applicability should be assured based on the use of reference models for the processes and resources inside a FSSN. Therefore five different companies offering field services were included in the project to assist the software design as depicted in table 2.

Table 2. Companies participating in the project

\begin{tabular}{lccccc}
\hline & Company 1 & Company 2 & Company 3 & Company 4 & Company 5 \\
\hline Employees & $>4,000$ & $>4,000$ & $>1,000$ & $>1,000$ & $<150$ \\
Revenue (CHF) & $>1$ bn. & $>500 \quad$ mio. & $>500 \quad$ mio. & $>300$ mio. & $<100$ mio. \\
& Industrial & Infrastructure/ & Machine tool & Machine tool & Medical \\
Industry & conglomerate & Construction & manufacturing & manufacturing & equipment \\
\hline
\end{tabular}

The main methodology for the development of the simulation framework embedded in the DSS was based on the guidelines provided by Bertrand (2002). The life cycle of a simulation study approach by Pidd [29] was used while guidelines proposed by Law and McComas [30] were considered as well. Different stakeholders, as for example service managers and field technicians, were already involved in the design phase of the DSS to support internal validity of the simulation framework and the usability of the software. 


\section{Decision Support System for Field Service Supply Networks}

The DSS is intended to support decision-making by the use of a discrete-event simulation framework to model FSSN. The process of service delivery can be designed based on predefined activities and includes normally at least the generation of random or planned service demand from machines in the field, the allocation these service tickets to technicians who then transfer to the assets, perform the required service and leave for home or the next asset. The input for the simulation model can be inputted via an adapted version of the Activiti process mapper, which represents a visual process mapping interface that includes drag-and-drop functionality and a data input interface including different tables and drop down cells that can be filled manually or imported from MS Excel. The simulation engine running in the background is based on the DesmoJ [31]. Next to the modules for data input, the DSS support the geographical visualization of assets, service technicians, and facilities based on OpenStreetMap and allows for performance analysis of the simulation runs in a comprehensive KPI module. Figure 1 shows the most important modules of the DSS.

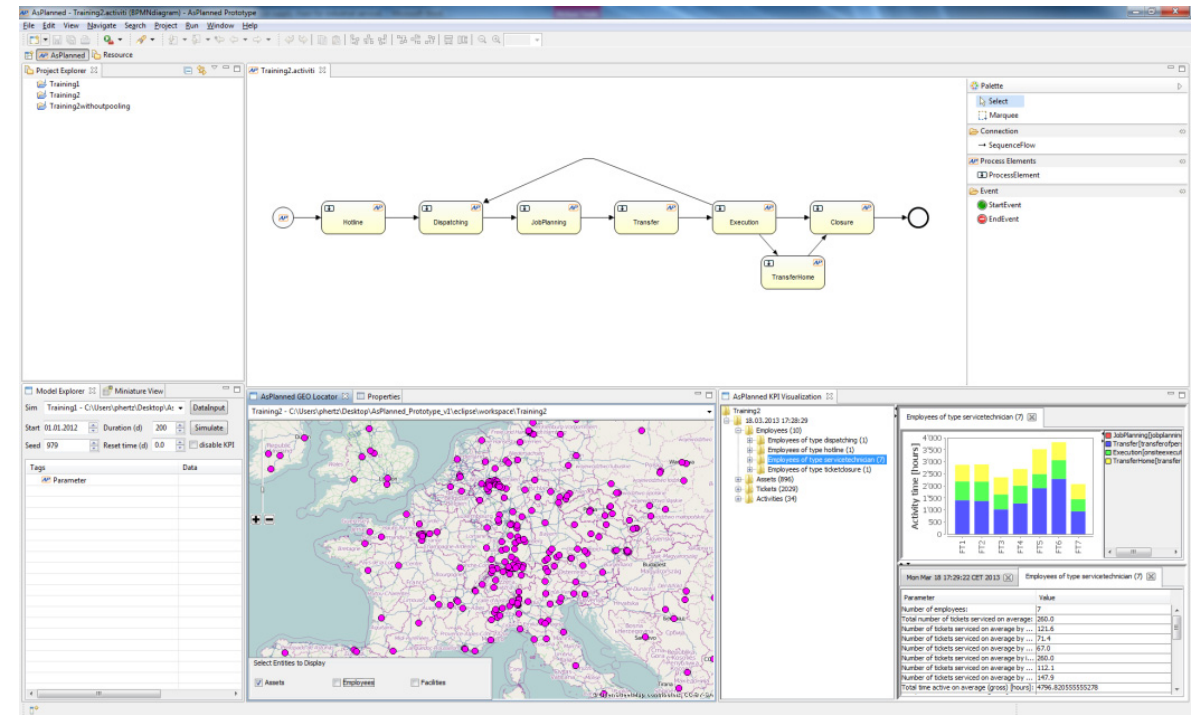

Fig. 1. General user interface of the AsPlanned Software

The simulation models are configured automatically based on the input of the user. The service delivery process is obtained from the Activiti process drawing while the data input data, e.g. for assets and technicians, are needed to create the different entities interacting in the FSSN. The main entities of the simulation framework are employees, assets, spare parts and service tickets. Only a few parameters are mandatory to construct a basic simulation model while a lot of detail can be added by including optional parameters in the models. Each predefined and enumerable parameter of an entity may also define the dimension for the calculation of operational parameters in the service delivery process (e.g. mean of processing time based on 
product and service type). Employees can be of different types, e.g. field technicians (FTs) or off-field staff (technical or non-technical). Various parameters include the skill, home location, shift, break and capabilities to perform the different activities. Assets consist of different items, which might represent modules of a machine, e.g. drive or control unit, and represent technical equipment as part of the installed base. Item may generate service tickets of different types based on the user input. Tickets represent service requests of a certain type for a specific item of an asset. Daily and weekly demand patterns can be inputted for each service type to allow for a realistic workload during the week while the time between the generations of two tickets can be modeled by various probability distributions. In addition to immaterial services, service parts (e.g. spares and tools) can also be modeled including parameters such as availability and replenishment time.

Activities are parts of the process and can be of 10 unique types that all have different parameters, e.g. the travel speed for transfer activities or the activity time for on-site service execution. During the activity "dispatching" tickets are assigned to FTs and placed in their job list. After finishing a job the employee conducts the activity "job planning" which refers to the selection of the next ticket for execution in the field. Various assignment algorithms for different service and shift types can be selected for both of these activities. Tickets in the field can be interrupted by breaks, the non-availability of parts, escalations in regard to capabilities or interruptions by high priority jobs. Transfer times are calculated based on the geographical distance that is obtained automatically by converting addresses in GPS coordinates via Google Maps.

\section{Improving Operations in the Field Service Supply Network}

The DSS has been used for evaluating different scenarios for all five companies being part of the project. In general the investigations can be clustered as local, with networks stretching over an area of less than $100 \mathrm{~km} 2$ up to the size of one country, and global for networks operating world or continent-wide. Performance was evaluated based on the response times and the total hours spent in the different activities.

In the following we will highlight three different investigations, two on a local (2 years simulation time) and one on global level (10 years simulation time). In a high density local network company 2 wanted to investigate the change of districting and qualification strategy by moving from a generalist's qualification profile with many decoupled districts to a specialist profile where up to 6 districts were accumulated on a regional layer. FTs were now dispatched based on their skill, distance to the customer and work load instead having a fixed assignment to their assets. While on-site execution times and therefore total hours spent on-site could be reduced by more than $6 \%$ due to better skill-job matches, travel time and response time were increasing by $14 \%$, respectively $13 \%$. On a global level the result of a generalization of the workforce and therefore better geographical dispatching was investigated as well and in a reduction of average response times by $23 \%$ while transfer times were $33 \%$ shorter. Another local network investigation was focused on the reduction of the number of technicians being able to conduct field work (with $32 \%$ of total work time spent in the field on average) by $10 \%$ and therefore increasing the time spent in the field for 
specialized FTs by $12.5 \%$. This resulted in the simulation in an increase of the response time for critical interventions with high priority by more than $22 \%$ and an increase in transfer times of $3 \%$.

\section{$6 \quad$ Limitations and Outlook}

The last paragraph has shown that the simulation-based DSS provides a huge potential to obtain meaningful quantitative results for difficult questions regarding the operations of FSSNs. Without a question results have to be investigated and understood well enough. During the projects the models have been improved in the level of detail in multiple cycles until results were obtained that could be understood in every detail. During the application of the tool as well as during the investigation of historical data for the data input interesting results were obtained, that improved the transparency of the service operations and capabilities of decision makers to improve operations.

Next to all benefits there are still limitations. Though the software reduces the time and cost effort for modeling significantly by building upon a generic framework, investigations with the DSS still mean a lot of work due to the data that was often not available in the required quality. Additionally the software is still at a prototype stage and has its limitations in respect to models sizes and simulation durations depending on the hardware used.

\section{References}

1. Baines, T.S., Lightfoot, H.W., Benedettini, O., Kay, J.M.: The servitization of manufacturing: A review of literature and reflection on future challenges. Journal of Manufacturing Technology Management 20, 547-567 (2009)

2. Alexander, W.L., Dayal, S., Dempsey, J.J., Vander Ark, J.D.: The secret life of factory service centers. The McKinsey Quarterly, 108-115 (2002)

3. Legnani, E., Cavalieri, S., Ierace, S.: A framework for the configuration of after-sales service processes. Production Planning \& Control 20, 113-124 (2009)

4. Gaiardelli, P., Saccani, N., Songini, L.: Performance measurement of the after-sales service network-Evidence from the automotive industry. Computers in Industry 58, 698-708 (2007), doi:10.1016/j.compind.2007.05.008

5. Dennis, A.M.J.K.: Service management: Building profits after the sales. Supply Chain Management Review 7, 42-48 (2003)

6. Metters, R., Marucheck, A., Metters Ann, R.M.: Service Management-Academic Issues and Scholarly Reflections from Operations Management Researchers. Decision Sciences 38, 195-214 (2007), doi:10.1111/j.1540-5915.2007.00156.x

7. Watson, E.F., Chawda, P.P., McCarthy, B., et al.: A Simulation Metamodel for ResponseTime Planning. Decision Sciences 29, 217-241 (1998)

8. Power, D.J., Sharda, R.: Decision support systems. Springer Handbook of Automation, 1539-1548 (2009)

9. Hertz, P., Finke, G.R., Schonsleben, P.: Industrial field service network planning: Existing methods in supply chain planning and modeling and their applicability for field services, pp. 258-263. IEEE (2012)

10. Colen, P.J., Lambrecht, M.R.: Product service systems: exploring operational practices. The Service Industries Journal, 1-15 (2012), doi:10.1080/02642069.2011.614344 
11. Chakravarthy, S.R., Agnihothri, S.R.: Optimal Workforce Mix in Service Systems with Two Types of Customers. Production and Operations Management 14, 218-231 (2005), doi:10.1111/j.1937-5956.2005.tb00020.x

12. Colen, P.J., Lambrecht, M.R.: Cross-training policies in field services. International Journal of Production Economics 138, 76-88 (2012), doi:10.1016/j.ijpe.2012.03.003

13. Klimberg Frederick, C.R., van, B., Klimberg, R.K., Van Bennekom, F.C.: Aggregate planning models for field service delivery. Location Science 5, 181-195 (1997)

14. Banerjee, D., Dasgupta, G., Desai, N.: Simulation-based evaluation of dispatching policies in service systems. In: Proceedings of the 2011 Winter Simulation Conference (WSC), pp. 779-791. IEEE (2011)

15. Hill, A.V.: An Experimental Comparison of Dispatching Rules for Field Service Support. Decision Sciences 23, 235-249 (1992)

16. Dear, R.G., Sherif, J.S.: Using Simulation To Evaluate Resource Utilization Strategies. Simulation 74, 75-83 (2000)

17. Hilla, A.V., Marcha, S.T., Nachtsheima, C.J., Shanker, M.S.: An Approximate Model for Field Service Territory Planning. IIE Transactions 24, 2-10 (1992)

18. Tang, Q., Wilson, G.R., Perevalov, E.: An approximation manpower planning model for after-sales field service support. Computers \& Operations Research 35, 3479-3488 (2008)

19. Abernathy, W.J., Baloff, N., Hershey, J.C., Wandel, S.: A Three-Stage Manpower Planning and Scheduling Model - A Service-Sector Example. Operations Research 21, 693711 (1973), doi:10.1287/opre.21.3.693

20. Dinh, T.T.L.: Manpower Capacity Planning Model Using a Queuing Approach for Ocè Nederland BV After-Sales Field Service Support. Technische Universiteit Eindhoven (2009)

21. Aggarwal, A.K.: Simulation as a DSS modelling technique. Information \&amp; Management 19, 295-305 (1990), doi:10.1016/0378-7206(90)90044-i

22. Mjema, E.A.M.: An analysis of personnel capacity requirement in the maintenance department by using a simulation method. Journal of Quality in Maintenance Engineering 8, 253-273 (2002)

23. Visser, J.K., Howes, G., Visser, G.J.K.H.: A simulation technique for optimising maintenance teams for a service company. South African Journal of Industrial Engineering 18, $169-185$ (2007)

24. Duffuaa, S.O., Raouf, A.: A simulation model for determining maintenance staffing in an industrial environment. Simulation 59, 93-99 (1992)

25. Colen, P., Lambrecht, M.: Cross training policies in a maintenance field service organization. Open Access publications from Katholieke Universiteit Leuven 46 (2010)

26. Agnihothri, S.R., Mishra, A.K.: Cross-training Decisions in Field Services with Three Job Types and Server-Job Mismatch. Decision Sciences 35, 239-257 (2004), doi:10.1111/j.00117315.2004.02642.x

27. Agnihothri, S.R., Mishra, A.K., Simmons, D.E.: Workforce Cross-Training Decisions in Field Service Systems with Two Job Types. The Journal of the Operational Research Society 54, 410-418 (2003)

28. Rapaccini, M., Visintin, F., Sistemi, A.: A simulation-based DSS for field service delivery optimization. In: The International Workshop on Modelling \& Applied Simulation - MAS (2008)

29. Pidd, M.: Computer modelling for discrete simulation. Wiley, Chichester (1989)

30. Law, A., Kelton, W.D.: Simulation Modeling and Analysis (1991), doi: citeulike-articleid:7549354

31. Liu, F., Luh, P.B., Moser, B., Kegg, R.L.: Scheduling and Coordination of Distributed Design Projects. CIRP Annals - Manufacturing Technology 47, 111-114 (1998), doi:10.1016/s0007-8506(07)62797-8 